\title{
Efficacy and safety of Id-protein-loaded dendritic cell vaccine in patients with multiple myeloma - Phase II study results
}

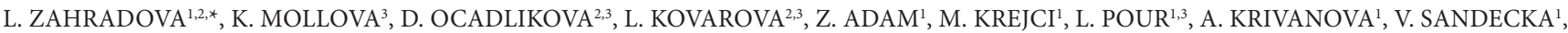 \\ R. HAJEK ${ }^{1,2,3}$
}

${ }^{1}$ Department of Internal Medicine-Hematooncology, University Hospital Brno and Masaryk University Brno, Jihlavska 20, 625 00, Brno, Czech Republic; ${ }^{2}$ LEHABI Department of Hematology University Hospital Brno, Jihlavska 20, Brno, Czech Republic; ${ }^{3}$ Babak Research Institute, Masaryk University, Kamenice 5, 62500, Brno, Czech Republic

*Correspondence: lzahradova@fnbrno.cz

Received October 27, 2011 / Accepted February 22, 2012

\begin{abstract}
In a phase II clinical study, pretreated multiple myeloma patients with relapsing or stable disease received autologous anticancer vaccine containing dendritic cells loaded with Id-protein. Patients received a total of 6 vaccine doses intradermally in monthly intervals. No clinical responses were observed. During the follow-up with a median of 33.1 months (range: 1143 months), the disease remained stable in 7/11 (64\%) of patients. Immune responses measured by ELISpot were noted in $3 / 11$ (27\%) and DTH skin test for Id-protein was positive in 8/11 (73\%) of patients; out of those, 1/11 (9\%) and 5/11 (46\%), respectively, had preexisting immune response to Id-protein before the vaccination began.

Outcomes were compared to those of a control group of 13 patients. A trend to lower cumulative incidence of progression in the vaccinated group was observed at 12 months from the first vaccination $(p=0.099)$. More patients from the control group compared to vaccinated patients required active anticancer therapy [4/11 (36\%) vs. 8/13 (62\%)].

Vaccines based on dendritic cells loaded with Id-protein are safe and induce specific immune response in multiple myeloma patients. Our results suggest that the vaccination could stabilize the disease in approximately two-thirds of patients.
\end{abstract}

Key words: dendritic cells, immunotherapy, anticancer vaccines, Id-protein, multiple myeloma

Multiple myeloma (MM) is the second most common hematological cancer. It is caused by clonal proliferation of plasma cells and is considered incurable. While approximately $30 \%$ of patients achieve complete remission, the disease invariably relapses months to years after first-line therapy [1,2]. This implies the presence of residual disease refractory to chemotherapy even in the setting of complete or nearly complete treatment response. In addition to standard chemotherapy and biological treatments, other treatment strategies are being developed with the aim of attacking the residual tumor population that cannot be destroyed using conventional therapies. One of these approaches uses patient's own immune system.

Tumor cells are immunogenic and cellular immunity plays a key role in the protection against cancer. Under certain conditions, the cells of the immune system are able to recognize tumor cells and destroy them.

The potential of the immune system to kill tumor cells has been clearly demonstrated in the setting of allogeneic transplantation of hematopoietic cells where the effect of graft versus disease has been successfully utilized. However, this strategy is associated with high mortality in MM patients and is applicable only in a small percentage of patients [3].

Cellular immunotherapy using anticancer vaccines is a novel, promising anti-cancer modality $[4,5,6]$.

In an effort to increase the efficacy of anticancer vaccines, cell-based vaccines have been tested in the past 10 years. These vaccines contain antigen-presenting cells capable of stimulating the immune system. Dendritic cells (DCs) are the most potent antigen-presenting cells and have the ability to process and present exogenous antigen to naive T lymphocytes $[7,8,9]$. The unique ability of DCs to present antigens plays a key role in the activation of cytotoxic T cells, generating specific immune responses directed against tumor cells [10]. MM plasma cells produce monoclonal immunoglobulin and the idiotype of the myeloma immunoglobulin (Id-protein) can be used as a unique tumor-associated antigen $[11,12,13,14,15,16]$. 
Between 2003 and 2004, a phase II clinical study was carried out at our institution testing the first generation of antitumour vaccines. MM patients received KLH-coupled Id-protein without antigen-presenting cells. Some immunological responses were noted (DTH test positivity, increased number of memory $\mathrm{B}$ cells), while no clinical responses to vaccination or toxicities were observed [17].

Here we present the results of a phase II clinical study in which the efficacy and toxicity of a vaccine containing DCs loaded with autologous Id-protein was tested in patients with relapsed MM who were not indicated for salvage chemotherapy.

\section{Patients and methods}

Study design. The vaccine was used in MM patients with stable disease or progression who did not require treatment with standard systemic therapy. All patients were pretreated. An interval of at least 3 months after the end of chemotherapy or maintenance therapy was required in order to allow the evaluation of treatment response to vaccination. The median interval from the end of previous treatment to the first of vaccination was 30.6 months ( 7.7 - 135.5 months). The minimal amount of monoclonal immunoglobulin on entry to the study was $5 \mathrm{~g} / \mathrm{L}$, so that the necessary amount of Id-protein could be isolated for the vaccine. The vaccine was administered intradermally 6 times (once monthly for 6 months); no adjuvant agents were used. The patients were periodically monitored for clinical and immunological response to vaccines. The minimal amount of DCs per one vaccine dose was $0.5 \times 10^{6}$. After the completion of study, patients received standard follow-up in 1- to 2-month intervals. Study was approved by the University Hospital Brno Ethics Committee and carried out in accordance with the Helsinki Declaration. Written informed consent was mandatory prior to enrollment.

Inclusion and exclusion criteria. Inclusion criteria: MM producing measurable level of serum M-Ig; M-Ig level $>5 \mathrm{~g} / \mathrm{L}$; stable disease or progression based on the European Group for Blood and Marrow Transplantation criteria [18]; no specific MM treatment(s) for al least 3 months prior to entering the study; no indication for treatment due to any organ and/or tissue damage caused by myeloma; no corticosteroid treatment for at least 3 months prior to the start of the study; liver enzyme levels lower than three times the upper limit of the norm; serum creatinine lower than twice the upper limit of the norm; and signed informed consent form.

Exclusion criteria: non-secreting myeloma; serious comorbidity with a negative impact on life expectancy; untreated newly diagnosed MM; possibility of pregnancy in women; definite or suspected sensitivity to compounds used in vaccine preparation; serious heart disease; acute infectious disease requiring antibiotic treatment; $\mathrm{pO} 2$ lower than $60 \mathrm{mmHg}$ at rest; significant dysfunction of vital organs; central nervous system metastases or a convulsive disorder; abnormal laboratory values including leukocytes $<4 \times 10^{9} /$ l, platelets $<100$ $\mathrm{x} 10^{9} / 1$, hematocrit $<30 \%$, billirubin above the upper limit of the norm, creatinine higher than double the upper limit of the norm, aspartate aminotransferase (AST) and/or alanine aminotransferase (ALT) higher than three times the upper limit of the norm.

Patients. Between June 2006 and January 2009, 12 patients were enrolled into the phase II clinical study. Of these patients, 11 with MM type IgG kappa received vaccination according to the protocol and were evaluable. One patient requested to be withdrawn from the study after receiving one dose of vaccine was not evaluated. The median age of the evaluable patients was 64 years (range: $51-75$ years) and the median of interval from diagnosis was 71 months (range: 25-160 months). All patients had been pretreated with one to four previous lines of systemic therapy. Nine out of 11 $(82 \%)$ were treated with autologous transplantation of hematopoietic cells; one patient (9\%) received two autologous transplantations. Three patients $(27 \%)$ had participated in a previous vaccination study with Id-protein. Results of a group of patients included into clinical evaluation were compared to a control group of 13 patients who went through the prescreening phase but eventually declined to participate in the study for reasons including long distance between their home and the study site in $10 / 13$ patients, poor mobility in $2 / 13$ patients, and other reason in one patient. No patient in the control group had participated in the previous vaccination study with Id-protein. There were no statistically significant differences in basic disease characteristics between the two groups of patients. Detailed characteristics of patients are shown in Table 1.

Preparation of Id-protein. Id protein was isolated from peripheral blood by affinity chromatography. Isolation was done on a protein-G column (Sigma P4691; capacity of column was $30 \mathrm{mg} \mathrm{Ig} / 1 \mathrm{ml}$ of Protein G). Unbound fractions were removed by washing with $25-50 \mathrm{ml}$ of physiological solution (PBS, pH 7.3). Elution of bound protein was carried out with $0.2 \mathrm{M}$ glycine $(\mathrm{pH} 2.7)$. Individual fractions $(0.9 \mathrm{ml})$ were immediately neutralized by adding $0.1 \mathrm{ml}$ of $1 \mathrm{M}$ Tris-base. Protein content in the fractions was measured by absorbance at $280 \mathrm{~nm}$. The presence of bacterial endotoxins was excluded by the LAL test (Limus Amebocyte Lysate, Bio Whittaker).

Preparation of dendritic cells. Dendritic cells (DCs) of patients were cultured from mononuclear cells isolated from heparinized peripheral blood of patients according to a GMP protocol for 9 days in the presence of GM-CSF and IL-4. DCs were prepared before each vaccine application. DCs were cultured in a medium X-VIVO 10 (BioWhittaker, Walkersville, MD, USA) with $50 \mathrm{mg} / \mathrm{l}$ gentamycin, $2 \mathrm{mM}$ L-glutamin, $25 \mathrm{mg} /$ $\mathrm{ml}$ HEPES buffer, and with $10 \%$ inactivated human $\mathrm{AB}$ serum (Sigma-Aldrich, St. Louis, USA) after density gradient centrifugation from adherent fraction after 2 hours of culture (X-VIVO 10 medium with $50 \mathrm{mg} / \mathrm{l}$ gentamycin, $2 \mathrm{mM}$ L-glutamin, $25 \mathrm{mg} /$ $\mathrm{ml}$ HEPES buffer, $80 \mathrm{U} / \mathrm{ml}$ DNAse, and with $10 \%$ inactivated human $\mathrm{AB}$ serum; $37^{\circ} \mathrm{C}, 5 \% \mathrm{CO}_{2}, 4,5 \% \mathrm{O}_{2}$ ). GM-CSF (BruCells, 


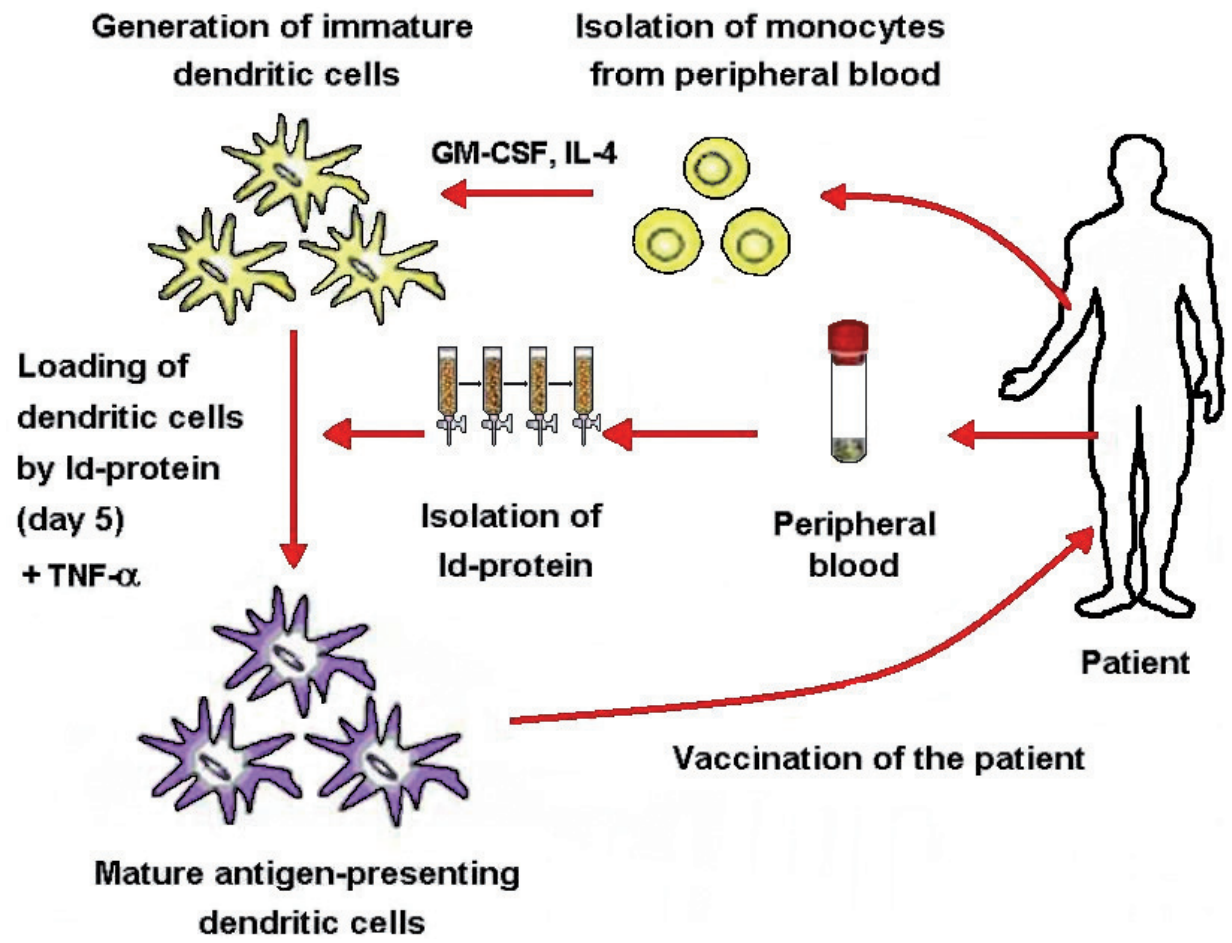

Figure 1. Vaccine preparation.

Table 1. Patients' characteristics

\begin{tabular}{|c|c|c|c|}
\hline & Vaccinated patients & Control group & p-value \\
\hline Number of patients & $\mathrm{N}=11$ & $\mathrm{~N}=13$ & \multirow{3}{*}{0.697} \\
\hline Female & $7(63.6 \%)$ & $7(53.9 \%)$ & \\
\hline Male & $4(36.4 \%)$ & $6(46.1 \%)$ & \\
\hline Age & $\mathrm{N}=11$ & $\mathrm{~N}=13$ & \multirow{4}{*}{0.835} \\
\hline Average & 63.8 years & 63.2 years & \\
\hline Median & 64 years & 62 years & \\
\hline Min-max & $51-75$ years & 54-80 years & \\
\hline Time from diagnosis & $\mathrm{N}=11$ & $\mathrm{~N}=13$ & \multirow{4}{*}{0.402} \\
\hline Average & 78.6 months & 65.1 months & \\
\hline Median & 71 months & 55 months & \\
\hline Min-max & 25-160 months & 19-135 months & \\
\hline D-S Clinical stage & $\mathrm{N}=11$ & $\mathrm{~N}=13$ & \multirow{4}{*}{0.889} \\
\hline I & $4(36.4 \%)$ & $4(30.8 \%)$ & \\
\hline II & $3(27.3 \%)$ & $3(23.1 \%)$ & \\
\hline III & $4(36.4 \%)$ & $6(46.2 \%)$ & \\
\hline ISS clinical stage & $\mathrm{N}=9$ & $\mathrm{~N}=11$ & \multirow{4}{*}{0.433} \\
\hline 1 & $6(66.7 \%)$ & $8(72.7 \%)$ & \\
\hline 2 & $2(22.2 \%)$ & $3(27.3 \%)$ & \\
\hline 3 & $1(11.1 \%)$ & $0(0.0 \%)$ & \\
\hline Previous treatment & $\mathrm{N}=11$ & $\mathrm{~N}=13$ & \multirow{4}{*}{0.889} \\
\hline 1 line & $7(63.6 \%)$ & $7(53.8 \%)$ & \\
\hline 2 lines & $2(18.2 \%)$ & $3(23.1 \%)$ & \\
\hline$\geq 3$ lines & $2(18.2 \%)$ & $3(23.1 \%)$ & \\
\hline \multicolumn{4}{|l|}{ FISH results } \\
\hline $\mathrm{RB} 1$ positive & $1 / 4$ & $2 / 9$ & \\
\hline p53 positive & $0 / 3$ & $1 / 9$ & \\
\hline IgH rearrangement & $0 / 3$ & $2 / 5$ & \\
\hline $\mathrm{t}(4 ; 14)$ positive & $0 / 3$ & $0 / 8$ & \\
\hline gain(1q21) positive & $0 / 3$ & $4 / 7$ & \\
\hline hyperdiploidy & ND & ND & \\
\hline
\end{tabular}

Brussels, Belgium) and IL-4 (BruCells) were added on the first day $(100 \mathrm{ng} / \mathrm{ml}$ and $800 \mathrm{U} / \mathrm{ml}$, respectively) and on day $4(200 \mathrm{ng} /$ $\mathrm{ml}$ and $1600 \mathrm{U} / \mathrm{ml}$, respectively). On day 5 of culture, DCs were loaded with Id-protein (50ug/ml of medium); on day 6 of culture, DCs were fully matured using TNF- $\alpha$. On days 0 and 9 of culture, viability of cells was measured and on days 0,5 , and 9 their morphology was evaluated. Cell viability on the day of administration was required to be $\geq 80 \%$. To evaluate the safety of vaccine, we carried out tests for the presence of mycoplasma (day 8), bacterial endotoxin (day 8) and microbiological testing of sterility including Gramm-Giemsa staining (day 8), aerobic and anaerobic culture (day 5), aerobic culture of supernatant after cell harvest (day 9). The maximum allowed amount of endotoxin was $\leq 350 \mathrm{U} / \mathrm{ml}$ of vaccine. Negative result of mycoplasma and microbiology tests were required. Immunophenotyping of DCs was performed by flow cytometry on days 0,5 , and 9 of culture. The following markers were measured: CD3, CD14, HLA-DR, CD80, CD 83, CD86, and HLA-DR/CD80 and HLA-DR/CD86 combinations. The positivity of HLA-DR/CD86 and/or HLA$\mathrm{DR} / \mathrm{CD} 80$ had to be $\geq 80 \%$ before administration of vaccine. The minimum amount of DCs was $0.5 \times 10^{6}$ per vaccine dose. Schema of vaccine preparation is shown in Figure 1.

Monitoring of clinical and immunological responses. Treatment efficacy was evaluated according to the European Group for Blood and Marrow Transplantation criteria [18].

Stimulation of specific immune response was evaluated using ELISpot and the skin DTH test (delayed type hypersensitivity) after intradermal administration of Id-protein 
[15]. 0.1mg of Id-protein was used for the DTH test. The test was considered positive when erythema and/or induration at the site of Id-injection was observed within 7 days after injection.

ELISpot was used to assess the activation of the immune system, detecting the production of intracellular interferon gamma at the cellular level. Commercial ELISpot Interferon- $\gamma$ Assay Kit (AID ELISpot Reader System, Germany) was used according to the manufacturer's instructions. The results were evaluated by AID ELISpot 3.0 software. DCs loaded with Idprotein were used to stimulate T lymphocytes, the time of incubation was 24 hours in a medium X-VIVO 15 (BioWhittaker, Walkersville, MD, USA) with $10 \%$ inactivated human AB serum (Sigma-Aldrich, St. Louis, USA). DC:T lymphocyte ratio was $1: 2$. T lymphocytes counts per assay were $0.1 \times 10^{6}$, $0.2 \times 10^{6}$ or $0.3 \times 10^{6}$. X-VIVO 15 with $10 \%$ human $\mathrm{AB}$ serum was used as negative control, while T lymphocytes cultured without antigen with $2 \mu \mathrm{g} / 100 \mu \mathrm{l}$ of phytohemaglutinin (SigmaAldrich, St. Louis, USA) were used as positive control. The source of both cell types was heparinized peripheral blood, which was processed immediately after collection by density gradient centrifugation. T lymphocytes were frozen after collection in a DMSO solution (1 part of DMSO and 9 parts of bovine fetal serum) and stored at $-80^{\circ} \mathrm{C}$. DCs were prepared as described above. $\mathrm{T}$ lymphocytes were thawed rapidly at $37^{\circ} \mathrm{C}$, immediately transferred to X-VIVO 15 medium with $10 \%$ human $\mathrm{AB}$ serum, centrifuged and cultured for 48 hours in the same medium before adding to assay. The number and viability of cells were evaluated in a Buerker's chamber. Viability of T lymphocytes was required to exceed $80 \%$. ELISpot was considered evaluable if the following criteria were met: number of spots $>50$ for the positive control and $<10$ for the negative control. ELISpot was considered positive if the number of spots was at least double over the baseline at any time point during the follow-up.

Cytokine production of IL-10 and IL- 12 by DCs was evaluated by ELISA. Commercial Human IL-12 US UltraSenzitiv (Biosource International, CA, USA) and IL-10 EASIA (Biosource Europe S.A., Nivelles, Belgium) were used according to manufacturer's instructions. Results were evaluated by software KIM, version 5.25. 50ug of medium was used for each reaction. Levels of cytokines were evaluated on days 0 , 3, 5 and 9 of incubation. Decrease of IL-10 and/or increase of IL-12 levels were considered to be suitable results.

Unspecific changes in leukocyte subpopulations were evaluated using a comprehensive flowcytometric panel. The following markers and their combinations were used: CD3, CD4, CD8, CD19, CD16+CD56, CD69, CD25, CD28, CD45RA, CD45RO, CD83, HLA-DR, lineage cocktail (lin), CD11c, CD123.

ELISpot and the DTH test were done at baseline and then in the $3^{\text {rd }}, 6^{\text {th }}, 9^{\text {th }}$ and $12^{\text {th }}$ month after first vaccination. The flowcytometric panel was evaluated monthly before each vaccine was administered. To evaluate the development of autoimmunity, a basic autoimmunity screen including anti- thyreoglobulin IgG, anti-pancreas cells IgG, anti-nuclear antibody, anti-streptolysin O (ASLO), rheumatoid factor, and $\mathrm{IgE}$ total was performed before the first vaccination and after the completion of study treatment. Immunological monitoring was not carried out in the control group.

Statistical analysis. Results were evaluated using Statistica 8.0 StatSoft CR software. For statistical comparison of changes of parameters in reference to entry value, the nonparametric Wilcoxon matched paired test was used. The level of significance was set at $\alpha=0.05$. Basic statistics (number of values, median, range) was used to evaluate vaccine parameters. To describe the data set, absolute and relative frequencies of values were calculated. Comparisons between group of vaccinated patients and control group for age and time since diagnosis were done by T-test (due to normal data distribution evaluated by the Shapiro-Wilk $\mathrm{W}$ test). Comparisons between the vaccinated patients and the control group in categorial parameters were tested by the Fisher exact test or the M-L $\chi^{2}$ test.

Comparisons of the probability of disease status change from stable disease to progression between the two groups were evaluated by the Fisher exact test. Time to progression was calculated using the Kaplan-Meier method and GehanWilcoxon test was used for comparisons of survival times.

\section{Results}

Vaccine parameters. A total of 74 vaccine samples were prepared for 12 patients; $90.5 \%$ of vaccines $(67 / 74)$ were actually administered. Six vaccines $(8.1 \%)$ did not meet safety criteria and in one case (1.4\%), the vaccine was not administered because of low DC count.

The median count of harvested peripheral blood mononuclear cells was $60 \times 10^{6}$ per patient and the median of $6.4 \times 10^{6}$ DCs were obtained $\left(0.89-36.96 \times 10^{6}\right)$. The cells were counted on days 0,5 , and 9 . The DC yields varied considerably among patients as well as in repeated cultures in the same patient. The median vitality of all 67 vaccines on day of administration was $92.0 \%$ (50.2\% - 98.9\%). Safety criteria were met for all 67 administered vaccines. When all qualitative criteria were not met, criteria for vaccine administration were the total number of DCs.

Functional characteristics of DCs were verified by immunophenotyping of co-stimulatory molecules and on the day of administration, $93.0 \%$ of cells in the vaccines were HLADR/CD86 positive $(40.4 \%$ - 99.30\%) (Table 2).

Changes in cytokine IL-10 and IL-12 production by DCs during cultivation were evaluated. Decrease in IL-10 levels or increase of IL-12 levels were observed in 50/68 and 6/52 vaccines, respectively. The levels were usually near the lower limit of detection. Median values of IL-10 and IL-12 for each patient are shown in Table 3.

Evaluation of clinical and immunological responses to vaccination. Before the start of the study, the disease status in 11 evaluable patients was as follows: stable disease in 10/11 
Table 2. Imunofenotyping of dendritic cells.

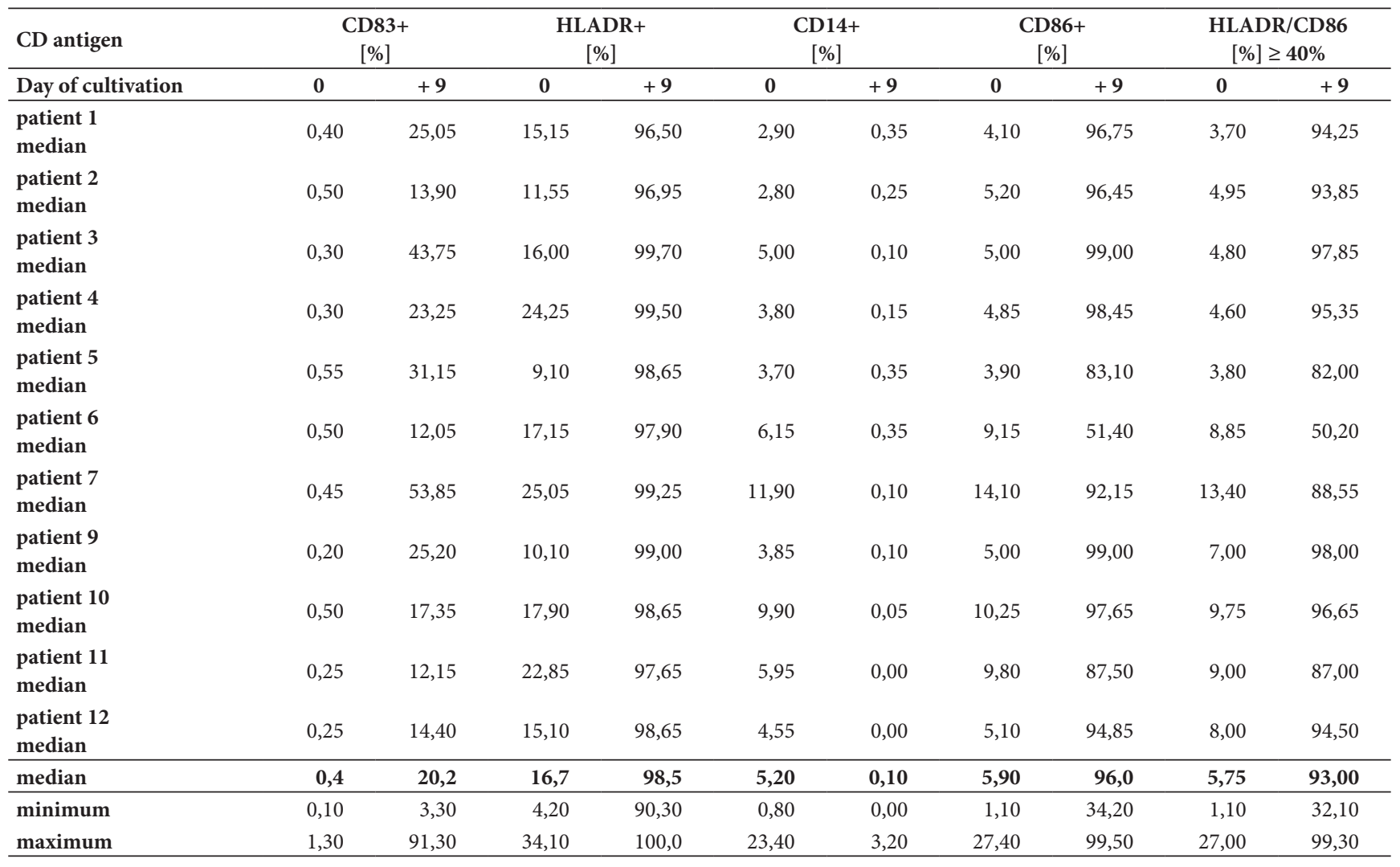

(91\%) of patients, progression without any signs/symptoms of organ or tissue damage in 1/11 (9\%) patients. During the 12-month follow-up, 3/11 (73\%) of patients had stable disease and $3 / 11(27 \%)$ of patients progressed (Figure 2). Specific anticancer treatment during vaccination was not required in any of the patients. At one year from the first vaccination, $4 / 11(36 \%)$ of patients required further therapy for MM. The

Table 3. IL-10 and IL-12 production by dendritic cells. Medians of production for all vaccines are shown in $\mu \mathrm{g} / \mathrm{ml}$

\begin{tabular}{lcccc}
\hline & \multicolumn{2}{c}{ IL-10 $(\mu \mathrm{g} / \mathrm{ml})$} & \multicolumn{2}{c}{ IL-12 $(\mu \mathrm{g} / \mathrm{ml})$} \\
\cline { 2 - 5 } & Day 0 & Day 9 & Day 0 & Day 9 \\
\hline Patient 1 & 13.2 & 18.2 & 0 & 0 \\
Patient 2 & 16.4 & 0 & 0.84 & 1.61 \\
Patient 3 & 0.76 & 13.1 & 1.85 & 1.07 \\
Patient 4 & 9.52 & 9.02 & 0.17 & 0.09 \\
Patient 5 & 0 & 0 & 0 & 8.15 \\
Patient 6 & 0 & 0 & 0 & 0 \\
Patient 7 & 0 & 0 & 3.1 & 0 \\
Patient 9 & 0 & 0 & 0 & 0 \\
Patient 10 & 0 & 0 & 14.22 & 7.22 \\
Patient 11 & 17.47 & 13.93 & 0 & 0 \\
Patient 12 & 0 & 3.12 & 0 & 0 \\
\hline
\end{tabular}

median interval to starting further therapy was 19.3 months (13-23.5). The rest of patients (6/11, i.e. 54\%) still had stable disease at the data cut-off, while one patient (9\%) had progressed but did not require further active treatment. The median follow-up since the first vaccination was 33 months (range: 11-43 months).

Initial disease status of patients in the control group was as follows: stable disease in $12 / 13(92.3 \%)$ of patients, and progression in $1 / 13(7.7 \%)$ of patients. During the follow-up, $8 / 13(62 \%)$ of patients required myeloma-directed treatment within 12 months, while 5/13 (38\%) of patients did not require any treatment. Stable disease was observed in $6 / 13$ $(46 \%)$ of patients, while $7 / 13$ (54\%) of patients progressed (Figure 3). There was a large numerical difference between the two groups when comparing the interval to starting further anticancer treatment $[4 / 11(36 \%)$ vs. $8 / 13(62 \%)]$ but the difference was not statistically significant (p-value 0.414 ). Cumulative incidences of progression during 12 months from the start of study between the two groups compared by Fisher exact test of independence were not statistically significant ( $p$-value 0.099). There was a trend to longer duration of stable disease in the vaccinated group (median 22 vs. 55 months; $\mathrm{p}=0.069$ ) evaluated by Kaplan-Meier method and Gehan-Wilcoxon test (Figure 4). Evaluation of disease status is shown Table 4. 


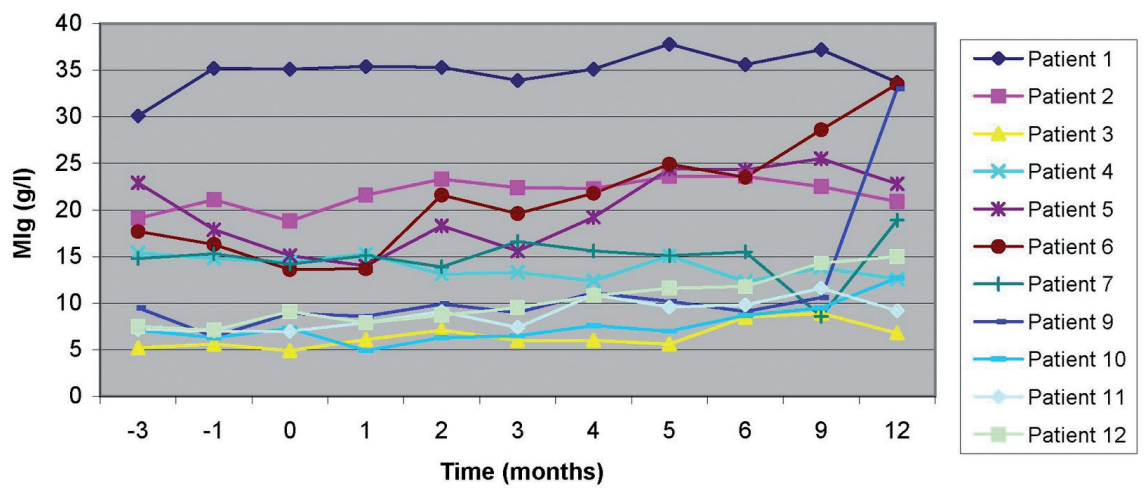

Figure 2. Development of M-Ig in vaccinated patients.
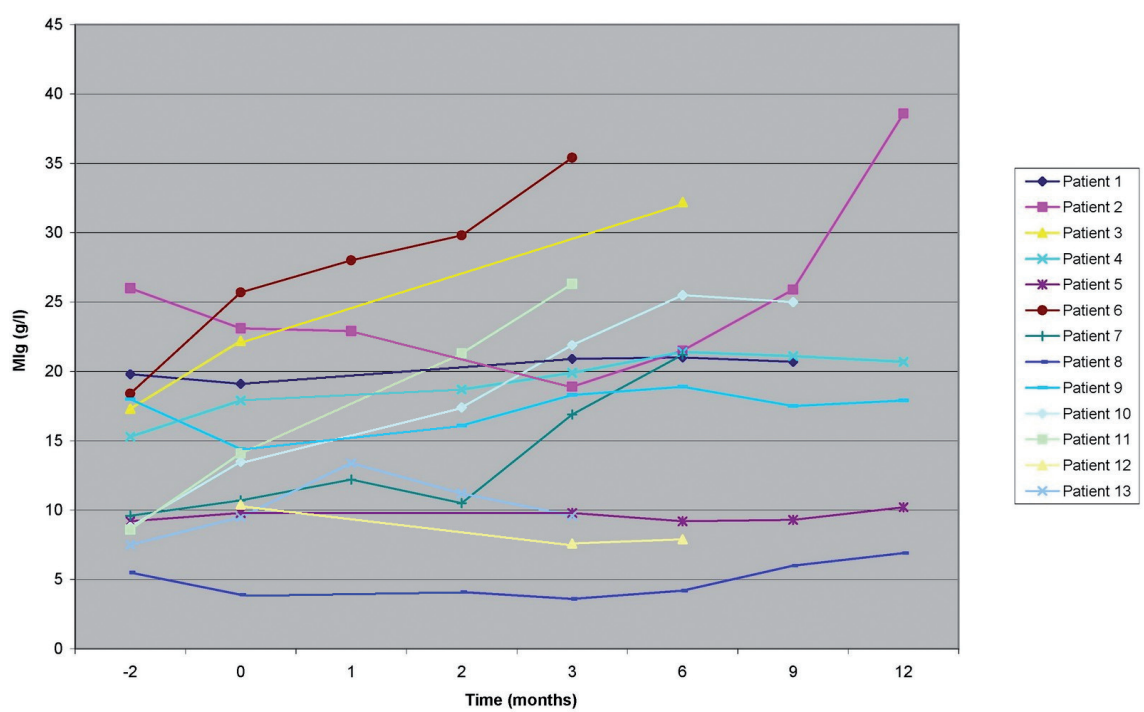

Figure 3. Development of M-Ig in the control group.

Table 4. Evaluation of disease.

\begin{tabular}{llll}
\hline & Vaccinated patients & Control group & p-value \\
\hline Disease before treatment & $\mathrm{N}=11$ & $\mathrm{~N}=13$ & 0.889 \\
Stable disease & $10(90.9 \%)$ & $12(92.3 \%)$ & $1(7.7 \%)$ \\
Progression & $1(9.1 \%)$ & $\mathrm{N}=13$ & $6(46.2 \%)$ \\
\hline Disease during one year follow-up & $\mathrm{N}=11$ & $7(53.8 \%)$ & 0.371 \\
Stable disease & $8(72.7 \%)$ & $\mathrm{N}=12$ & $5(41.7 \%)$ \\
Progression & $3(27.3 \%)$ & $7(58.3 \%)$ & 0.099 \\
Changes in stable disease during one-year follow up & $\mathrm{N}=10$ & $\mathrm{~N}=13$ & 15 months \\
No change & $8(80.0 \%)$ & $10-15$ months & 0.186 \\
Worse (from stable disease to progression) & $2(20.0 \%)$ & $\mathrm{N}=8$ \\
Length of follow-up & $\mathrm{N}=11$ & 5.5 months \\
Median & 33.1 months & $2-10$ months \\
\hline Min-max & $11-43$ months & 0.414 \\
Start of anticancer treatment ${ }^{\mathrm{a}}$ & $\mathrm{N}=4$ & 19.25 months & \\
Min-max & $13-23.5$ months & \\
\hline
\end{tabular}

${ }^{a}$ in case of vaccinated patients from start of vaccination, in case of control group since exclusion from study (11/2008) 


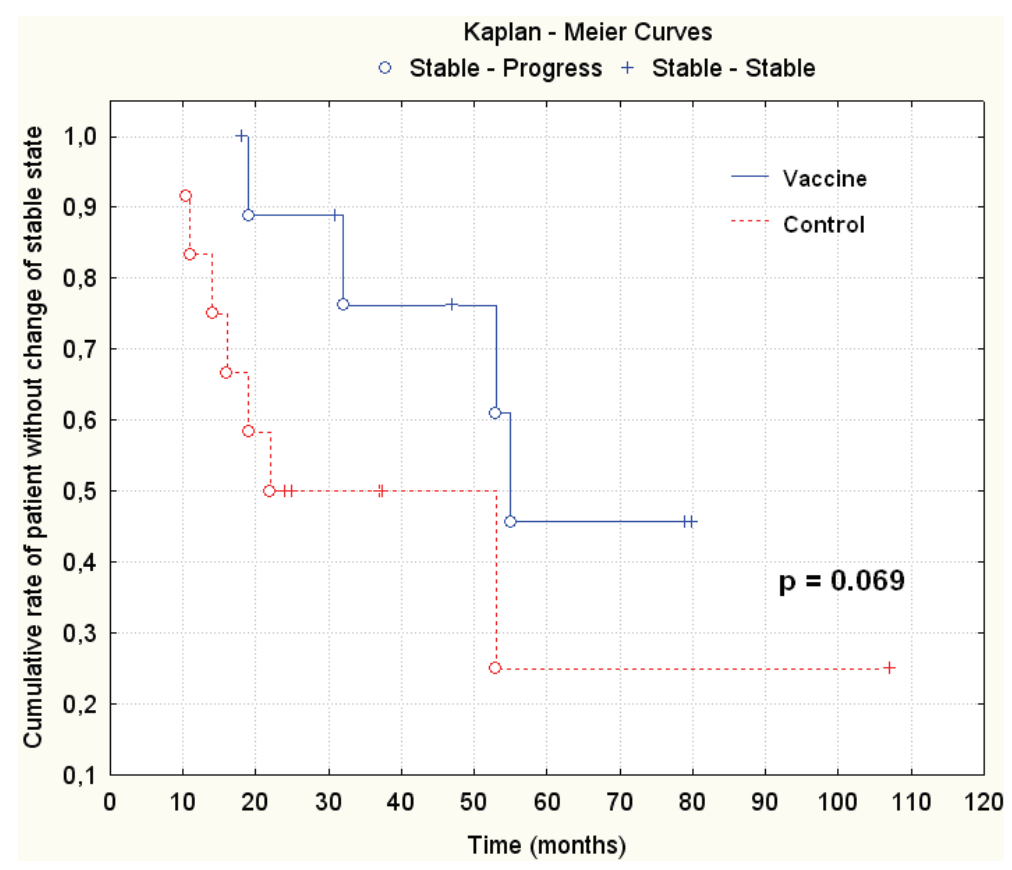

Figure 4. Time to progression of the vaccinated patients and of the control group.

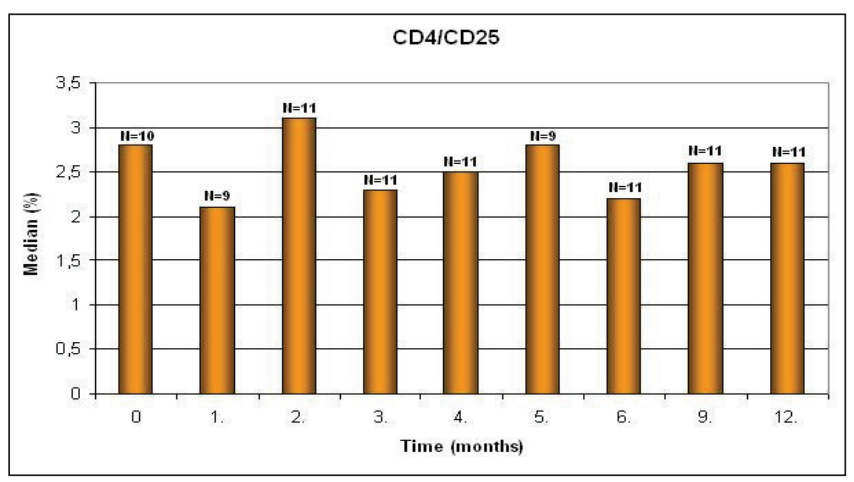

Figure 5. Flowcytometric evaluation of selected parameters.

Immunological responses measured by ELISpot were observed in $2 / 11$ (18\%) of patients in the $9^{\text {th }}$ month (46 spots) and the $3^{\text {rd }}$ month (12 spots) after the first vaccination, respectively. In one patient $(1 / 11,9 \%$, ) there was an immunological response to Id-protein before vaccination that gradually decreased during the follow-up $(205,110,197$, and finally to 120 spots). Four of 11 (36\%) patients did not have any immunological response detectable by ELISpot. The test was not evaluable in $4 / 11(36 \%)$ patients.

One of the two patients with positive ELISpot response had been previously vaccinated using Id-protein coupled with KLH and administered together with IL-2 in a previous clinical trial [17]. However, the patient with the positivity of pre-vaccination ELISpot had not participated in the previous study. Both patients had stable disease during the study fol-

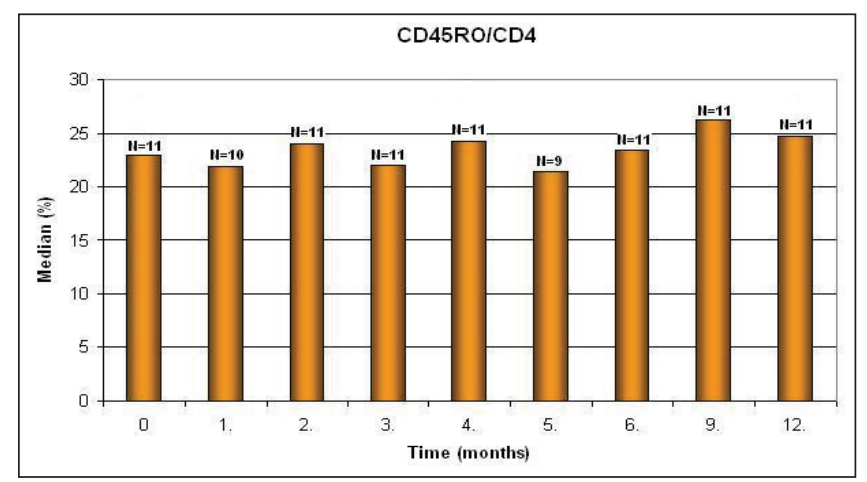

low-up. ELISpot was not evaluable in the other two patients who had participated in the previous vaccination study. Two out of 4 patients with negative immunological reaction to Id-protein progressed during the follow-up, including one patient who required further antimyeloma treatment, and two patients had stable disease. No significant correlation was found between the results of ELISpot and the clinical course of disease, nevertheless the analysis was limited by the small number of patients.

DTH skin for Id-protein test became positive in 3/11 (27\%) of patients, remained negative in 3/11 (27\%) of patients, and $5 / 11(45 \%)$ of patients had immunological response Id-protein before the start of vaccination. Of the three patients $(3 / 11,27 \%)$ who had been enrolled in the previous vaccination study, two patients had DTH test positive on entry and remained without 
anticancer treatment while the third patient had no reaction to DTH test and had to start anticancer treatment during the 12-month follow-up. Two of 3 patients with negative DTH test as well as $2 / 3$ of patients with positive DTH test had to start other active treatment within 12 months of enrollment. None of 5 patients with positive Id-protein-specific DTH test on entry required treatment during the follow-up. No association was detected between DTH test results and the clinical course of disease.

Summarized results of clinical and immunological evaluation are shown in Table 5, and representative results of the DTH test are shown in Table 6.

No significant changes were observed in the evaluated flowcytometric parameters (T, B, NK cells), including the populations of naïve (CD45RA+/CD4+, CD45RA+/ CD8+), memory (CD45RO+/CD4+, CD45RO+/CD8+), regulatory $(\mathrm{CD} 4+/ \mathrm{CD} 25+)$ and suppressor $\mathrm{T}$ lymphocytes (CD8+/CD28-) and populations of dendritic cells (CD83+/ HLA-DR+/CD11c+, CD83+/HLA-DR+/CD123+, lin-/HLADR+/CD11c+, lin-/HLA-DR+/CD123+) (Figure 5).

No statistically significant associations between the initial clinical status of disease and immunological responses to vaccine were observed. It is important to realize that only a small number of patients was tested and the analysis could have been biased because of these small numbers. In the control group, these measurements were not carried out.
Vaccination toxicities. No serious toxicities were noted during the study and most reactions to the vaccine were local and self-limiting. In $43.3 \%(29 / 67)$ of vaccinations, there was local redness in the area of injection. In $44.8 \%(30 / 67)$ of cases, there was induration. The median duration of local reaction was 4 days (range: 1-7 days). In one patient, increased temperatures up to $37.2^{\circ} \mathrm{C}$ was observed after each vaccination. Only grade 1-2 toxicities occurred and most of them were probably unrelated to the vaccination. They included upper respiratory infection, urinary infection, labial herpes simplex reactivation, skin abscess, joint pain, and humerus fracture after an accident. Three serious adverse events were observed, in all cases without any connection with the vaccination. In one case, the patient required hospital admission because of uncontrolled hypertension diagnosed before the administration of a vaccine; the two other cases occurred in one patient and consisted of recurrent urinary infection in a patient with neurogenic bladder with the need for regular self-catheterization. Throughout the entire follow-up, no signs or symptoms of autoimmune disease were noted in any of the vaccinated patients.

\section{Discussion}

Immunotherapy including DCs-based vaccination has been tested at different institutions in recent years. Id-protein was the most commonly used tumor antigen. Id-protein is a unique

Table 5. Summarized results of immunological and clinical evaluation.

\begin{tabular}{|c|c|c|c|c|c|c|}
\hline & ELISpot & DTH test & Entry disease status & $\begin{array}{l}\text { Disease status during } \\
12 \text { months }\end{array}$ & $\begin{array}{l}\text { Progression - long- } \\
\text { term follow-up }\end{array}$ & Treatment \\
\hline Patient 1 & $\mathrm{NE}$ & positive & stable & stable & yes & yes \\
\hline Patient 3 & $\mathrm{NE}$ & positive on study entry & stable & stable & no & no \\
\hline Patient 4 & $\mathrm{NE}$ & positive on study entry & stable & stable & no & no \\
\hline Patient 5 & positive & positive on study entry & stable & stable & no & no \\
\hline Patient 6 & $\mathrm{NE}$ & positive & progression & progression & NA & yes \\
\hline Patient 7 & positive on study entry & & stable & stable & no & no \\
\hline Patient 9 & negative & negative & stable & progression & NA & yes \\
\hline Patient 10 & negative & negative & stable & stable & no & no \\
\hline Patient 11 & negative & positive & stable & stable & no & no \\
\hline Patient 12 & negative & positive on study entry & stable & progression & NA & no \\
\hline
\end{tabular}

NE - not evaluable; NA - not aplicable

Table 6. Representative DTH test results.

Size of induration after aplication of Id-protein in $\mathrm{mm}$ is shown. Induration was evaluated in 24-hour intervals until resolution.

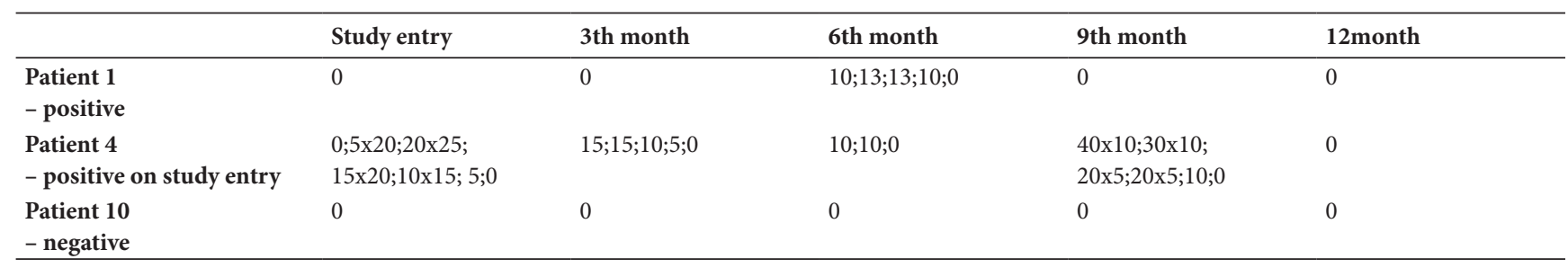


protein specifically produced by myeloma cells and thus useful for the production of highly selective antitumor vaccines $[19,20]$. Id-protein alone is only weakly immunogenic but its immunogenicity can be potentiated by conjugation with a strong immunogen such as keyhole limpet hemocyanine or by its presentation on dendritic cells $[14,16,17]$. Despite high hopes, results of vaccination studies have been disappointing in terms of clinical efficacy. While immunological responses have been occasionally observed, clinical responses occurred only in a small number of patients $[14,16,21,22]$.

One possible reason for this failure could be that cytokines used for generation of DCs, such as GM-CSF, IL- 4 and TNF- $\alpha$, had an inhibitory effect on anti-cancer responses.

With the growing knowledge about DC biology and culture, new cytokine combinations are being tested in order to optimize DC culture for clinical applications [23]. IL-12 is considered the most important stimulatory cytokine and needs to be produced by DCs in sufficient quantities [23].

Nevertheless, several clinical studies comparing results of vaccinated patients with a control group of patients have been published demonstrating that despite the lack of detectable treatment responses, vaccines could prolong the time to progression or even overall survival. Long-term results of vaccination using an autologous Id-protein-based approach have been published by Coscia et al [4]. In their study, the vaccine was given to MM patients in the first remission. Their outcomes were compared to those of historical controls treated when maintenance therapy using interferon- $\alpha$ alone or in combination with corticosteroids. The authors reported that the time to progression and overall survival were comparable for both groups of patients. An encouraging study of idiotype-pulsed antigen-presenting cells vaccination following autologous transplantation in multiple myeloma patients has been recently published by Lacy et al [24]. While comparing a group of patients vaccinated after autologous stem cell transplantation with a control group undergoing autologous transplantation at the same time, a statistically significant difference was observed in overall survival favoring vaccination ( $p$-value 0.020). In the terms of TTP and PFS, no differences were seen. Nevertheless, these studies were limited by small numbers of patients.

Another limitation of published clinical studies is that vaccines are often administered shortly after systemic anticancer treatment. Thus, natural immunity may be suppressed by chemotherapy at the time of vaccination. In our study, the median interval from previous systemic treatment was 30.6 months, while in the majority of $10 / 12$ patients the treatment free interval was more than 1 year.

MM is a disease characterized by the failure of cellular and humoral immunity. Prabhala et al [25] showed that even responses to standard vaccinations are rather limited in MM and MGUS patients. Using hepatitis B vaccination as an example, they have shown that only approximately $30 \%$ of patients have antibody response to vaccination. In contrast, $90 \%$ of vaccinated healthy individuals had antibody response to hepatitis B vaccine. It is obvious that the development of clinically useful anticancer vaccines in MM is more complicated than in other cancers because of complex disruption of the immune system.

No direct treatment effect of vaccination has been seen in our study. Disease responses as defined by the standard criteria still remain to be seen in the setting of MM vaccination. Nevertheless, in comparison to the control group, more vaccinated patients remained in the phase of stable disease. Thus, it is probably critically important to vaccinate patients with disease stabilization as opposed to progressive disease. Another potentially useful strategy is to administer nontoxic and well-tolerated vaccines to patients with MGUS, to prevent or postpone development of overt MM. The use of immunomodulatory drugs in the clinical practice leaves an open window of opportunity for vaccinations and this class of agents might even enhance the effect of vaccines. It is obvious that further optimization of anticancer vaccines is necessary. Nevertheless, with minimal toxicity and large potential benefit, vaccination remains a promising modality in the fight against malignant diseases.

Acknowledgements: This project was supported by IGA MZCR NR8945, NR9225, NS9871, MUNI/A/1012/2009 and research projects of Ministry of Education, Youth and Sports: LC06027, NPVII 2B06058.

\section{References}

[1] ATTAL M, HAROUSSEAU JL, STOPPA AM, SOTTO JJ, FUZI$\mathrm{BET} \mathrm{JG}$, et al. A prospective, randomized trial of autologous bone marrow transplantation and chemotherapy in multiple myeloma. Intergroup Francois du Myelome. N Engl J Med 1996; 335: 91-7. http: //dx.doi.org/10.1056/NEJM199607113350204

[2] BARLOGIE B, TRICOT GJ, VAN RHEE F, ANGTUACO E, WALKER R, et al. Long-term outcome results of the first tandem autotransplant trial for multiple myeloma. $\mathrm{Br}$ J Haematol 2006; 135: 158-64. http: //dx.doi.org/10.1111/ j.1365-2141.2006.06271.x

[3] ROSENBLATT J, AVIGAN D. Cellular immunotherapy for multiple myeloma. Best Pract Res Clin Haematol 2008; 21: 559-77. http: //dx.doi.org/10.1016/j.beha.2008.07.007

[4] COSCIA M, MARIANI S, BATTAGLIO S, DI BELLO C, FJORD F, et al. Long-term follow-up of idiotype vaccination in human myeloma as a maintenance therapy after high-dose chemotherapy. Leukemia 2004; 18: 139-45 http: //dx.doi. org/10.1038/sj.leu.2403181

[5] TIMMERMAN JM, CZERWINSKI DK, DAVIS AT, HSU FJ, BENIKE C, et al. Idiotype-pulsed dendritic cells vaccination for B-cell lymphoma: clinical and immune response in 35 patients. Blood 2002; 99: 1517-26. http: //dx.doi.org/10.1182/ blood.V99.5.1517

[6] WIERECKY J, MULLER MR, WIRTHS S, HALDER-OEHLER E, DORFEL D, et al. Immunologic and clinical response after vaccinations with peptide-pulsed dendritic cells in metastatic renal cancer patients. Cancer Res 2006; 66: 5910-8. http: //dx.doi.org/10.1158/0008-5472.CAN-05-3905 
[7] HART DNJ. Dendritic cells: unique leukocyte populations which control the primary immune response. Blood 1997; 90: 3245-87.

[8] STEINMAN RM. Dendritic cells and immune-based therapies. Exp Hematol 1996; 24: 859-62.

[9] HAJEK R. BUTCH AW. Dendritic cell biology and application of dendritic cells to immunotherapy of multiple myeloma. Med Oncol 2000; 17: 2-15. http: //dx.doi.org/ $\underline{10.1007 / B F 02826210}$

[10] BUCHLER T, HAJEK R. Dendritic cell vaccines in the treatment of multiple myeloma. Med Oncol 2002; 19: 213-8. http: //dx.doi.org/10.1385/MO: 19: 4: 213

[11] KWAK LW, TAUB DD, DUFFEY PL, BENSINGER WI, BRYANT EM, et al. Transfer of myeloma idiotype-specific immunity from an actively immunised marrow donor. Lancet 1995; 345: 1016-20. http: //dx.doi.org/10.1016/S01406736(95)90757-2

[12] BERGENBRANT S, YI Q, OSTERBORG A, BJORKHOLM M, OSBY E, et al. Modulation of anti-idiotypic immune response by immunization with the autologous $\mathrm{M}$-component protein in multiple myeloma patients. Br J Haematol 1996; 92: 840-6. http: //dx.doi.org/10.1046/j.1365-2141.1996.419959.x

[13] OSTERBORG A, YI Q, HENRIKSSON L, FAGERBERG J, BERGENBRANT S, et al. Idiotype immunization combined with granulocyte-macrophage colony-stimulating factor in myeloma patients induced type I, major histocompatibility complex-restricted, CD8- and CD4-specific T-cell responses. Blood 1998; 91: 2459-66.

[14] TITZER S, CHRISTENSEN O, MANZKE O, TESCH H, WOLF J, et al. Vaccination of multiple myeloma patients with idiotype-pulsed dendritic cells: immunological and clinical aspects. Br J Haematol 2000; 108: 805-16. http: //dx.doi. org/10.1046/j.1365-2141.2000.01958.x

[15] MASSAIA M, BORRIONE P, BATTAGLIO S, MARIANI S, BEGGIATO E, et al. Idiotype vaccination in human myeloma: generation of tumor-specific immune responses after highdose chemotherapy. Blood 1999; 94: 673-83.

[16] CULL G, DURRANT L, STAINER C, HAYNES A, RUSSELL N. Generation of anti-idiotype immune responses following vaccination with idiotype-protein pulsed dendritic cells in myeloma. Br J Haematol 1999; 107: 648-55. http: //dx.doi. org/10.1046/j.1365-2141.1999.01735.x
[17] ZAHRADOVA L, BUCHLER T, SMEJKALOVA J, OCADLIKOVA D, KOVAROVA L, et al. Monoclonal immunoglobulin-derived vaccine in patients with multiple myeloma - phase II clinical study results. Klinická onkologie 2006; 1: 26-9.

[18] BLADE J, SAMSON D, REECE D, APPERLEY J, BJORKSTRAND B, et al. Criteria for evaluating disease response and progression in patients with multiple myeloma treated by high-dose therapy and haemopoetic stem cell transplantation. Myeloma subcommittee of the EBMT. European Group for Blood and Marrow Transplant. Br J Haematol 1998; 102: 1115-23. http: //dx.doi.org/10.1046/j.1365-2141.1998.00930.x

[19] LYNCH RG, GRAFF RJ, SIRISINHA S, SIMMS ES, EISEN HN. Myeloma proteins as tumor-specific transplantation antigens. Proc Natl Acad Sci USA 1972; 69: 1540-4. http: //dx.doi.org/10.1073/pnas.69.6.1540

[20] HOUET L, VEELKEN H. Active immunotherapy of multiple myeloma. Eur J Cancer 2006; 42: 1653-60. http: //dx.doi. org/10.1016/j.ejca.2006.03.008

[21] WEN YJ, LING M, BAILEY-WOOD R, LIM SH. Idiotypic protein-pulsed adherent peripheral blood mononuclear cellderived dendritic cells prime immune system in multiple myeloma. Clin Cancer Res 1998; 4: 957-62.

[22] LISO A, STOCKERL-GOLDSTEIN KE, AUFFERMANNGRETZINGER S, BENIKE CJ, REICHARDT V, et al. Idiotype vaccination using dendritic cells after autologous peripheral blood progenitor cell transplantation for multiple myeloma. Biol Blood Marrow Transplant 2000; 6: 621-7. http: //dx.doi. org/10.1016/S1083-8791(00)70027-9

[23] SKALOVA K, MOLLOVA K, MICHALEK J. Human myeloid dendritic cells for cancer therapy: Does maturation matter? Vaccine 2010; 28: 5153-60. http: //dx.doi.org/10.1016/ j.vaccine.2010.05.042

[24] LACY MQ, MANDREKAR S, DISPENZIERI A, HAYMAN S, KUMAR S, et al. Idiotype-pulsed antigen presenting cells following autologous transplantation for multiple myeloma may be associated with prolonged survival. Am J Hematol 2009; 84: 799-802. http: //dx.doi.org/10.1002/ajh.21560

[25] PRABHALA RH, EFEBERA YA, LEE S, HAN AJ, PELLURU $\mathrm{D}$, et al. Lack of response to vaccination in MGUS and stable myeloma. 51th ASH Annual Meeting. Abstract in: Blood 2009; 114: 734-5 (1852). 